\title{
Measurement of fine particles and smoking activity in a statewide survey of 36 California Indian casinos
}

\author{
RUO-TING JIANG ${ }^{\mathrm{a}}$, KAI-CHUNG CHENG ${ }^{\mathrm{a}}$, VIVIANA ACEVEDO-BOLTON ${ }^{\mathrm{a}}$, NEIL E. KLEPEIS ${ }^{\mathrm{a}}$, \\ JAMES L. REPACE ${ }^{\text {b,c }}$, WAYNE R. OTT ${ }^{a}$ AND LYNN M. HILDEMANN ${ }^{a}$ \\ ${ }^{a}$ Department of Civil and Environmental Engineering, Stanford University, Stanford, California, USA \\ ${ }^{\mathrm{b}}$ Department of Public Health and Family Medicine, Tufts University School of Medicine, Boston, Massachusetts, USA \\ ${ }^{\mathrm{c}}$ Repace Associates, Bowie, Maryland, USA
}

\begin{abstract}
Despite California's 1994 statewide smoking ban, exposure to secondhand smoke (SHS) continues in California's Indian casinos. Few data are available on exposure to airborne fine particles $\left(\mathrm{PM}_{2.5}\right)$ in casinos, especially on a statewide basis. We sought to measure $\mathrm{PM}_{2.5}$ concentrations in Indian casinos widely distributed across California, exploring differences due to casino size, separation of smoking and non-smoking areas, and area smoker density. A selection of 36 out of the 58 Indian casinos throughout California were each visited for $1-3 \mathrm{~h}$ on weekend or holiday evenings, using two or more concealed monitors to measure $\mathrm{PM}_{2.5}$ concentrations every $10 \mathrm{~s}$. For each casino, the physical dimensions and the number of patrons and smokers were estimated. As a preliminary assessment of representativeness, we also measured eight casinos in Reno, NV. The average $\mathrm{PM}_{2.5}$ concentration for the smoking slot machine areas $\left(63 \mu \mathrm{g} / \mathrm{m}^{3}\right)$ was nine times as high as outdoors $\left(7 \mu \mathrm{g} / \mathrm{m}^{3}\right)$, whereas casino non-smoking restaurants $\left(29 \mu \mathrm{g} / \mathrm{m}^{3}\right)$ were four times as high. Levels in non-smoking slot machine areas varied: complete physical separation reduced concentrations almost to outdoor levels, but two other separation types had mean levels that were 13 and $29 \mu \mathrm{g} / \mathrm{m}^{3}$, respectively, higher than outdoors. Elevated $\mathrm{PM}_{2.5}$ concentrations in casinos can be attributed primarily to SHS. Average $\mathrm{PM}_{2.5}$ concentrations during $0.5-1 \mathrm{~h}$ visits to smoking areas exceeded $35 \mu \mathrm{g} / \mathrm{m}^{3}$ for $90 \%$ of the casino visits. Journal of Exposure Science and Environmental Epidemiology (2011) 21, 31-41; doi:10.1038/jes.2009.75; published online 17 February 2010
\end{abstract}

Keywords: secondhand smoke, particulate matter, $P M_{2.5}$, casino, indoor air pollution, smoking activity.

\section{Introduction}

Exposure to secondhand smoke (SHS) has been implicated as a risk factor for cardiovascular diseases, pulmonary malfunction, lung cancer, and mortality (Brennan et al., 2004; Nazaroff and Singer, 2004; CDC, 2005; California EPA, 2006; Surgeon General, 2006). Barnoya and Glantz (2005) found brief exposures (minutes to hours) to SHS were associated with adverse cardiovascular effects nearly as large $(80-90 \%)$ as those experienced by chronic active smokers.

SHS is a major indoor source of airborne fine particles $\left(\mathrm{PM}_{2.5}\right)$, which have been associated with a range of acute and chronic diseases (Pope et al., 2001, 2009; U.S. EPA, 2006). Currently, 164 countries have adopted comprehensive or partial smoke-free legislation (Koh et al., 2007; WHO, 2009). As of April 2009, 15 states in the United States, plus

1. Address all correspondence to: Professor Lynn M. Hildemann, Department of Civil and Environmental Engineering, Stanford University, 473 Via Ortega, Rm. 391, Stanford, CA 94305, USA.

Tel.: +1650723 0819. Fax: +16507237058.

E-mail: hildemann@stanford.edu

Received 14 October 2009; accepted 17 December 2009; published online 17 February 2010
Washington DC, have enacted smoke-free laws in all workplaces, including bars and restaurants (ANRF, 2009).

California was the first state to enact a statewide ban on smoking in indoor workplaces. In 1994, California passed its Smoke-free Indoor Workplace Act, which prohibits smoking in enclosed places of employment (except tobacconists), including bars (1998) and restaurants. Some California towns and cities have subsequently passed stricter laws banning smoking outdoors near public buildings, in outdoor restaurant patios, and even in some apartment buildings. In 2007, California adopted a statewide law banning smoking in cars if children are present. However, due to the sovereign nation status of Indian tribes, exposure to SHS continues in nearly all California Indian casinos.

Indoor SHS in casinos imposes significant health risks on casino employees as well as on non-smoking patrons. Moreover, employees working on tribal reservations are not covered by California's worker safety laws (Dunstan, 1998). Earlier studies have found post-work shift or post-visit increases in the nicotine metabolite, cotinine, in casino employees and patrons (Trout et al., 1998; Wakefield et al., 2005; Abrams et al., 2006; Larsson et al., 2008; CDC, 2009; Repace, 2009). Two studies found increases in a tobaccospecific carcinogen in non-smoking casino patrons and 
dealers, respectively (Anderson et al., 2003; CDC, 2009). Other studies (Kado et al., 1991; Trout et al., 1998; Hammond, 1999) have examined airborne nicotine concentrations in casinos, and Larsson et al. (2008) reported that exposures for $87 \%$ of workers exceeded a nicotine threshold $\left(0.5 \mu \mathrm{g} / \mathrm{m}^{3}\right)$ associated with health risks. A survey of London casino workers (Pilkington et al., 2007) reported respiratory and sensory irritation symptoms associated with SHS exposure.

Exposures to SHS in hospitality locations and workplaces have been measured across the world (Siegel and Skeer, 2003; Hyland et al., 2008; López et al., 2008). However, the few published studies measuring fine particle concentrations inside casinos have considered relatively few casinos (Repace, 2004, 2009).

To the best of our knowledge, this study is the first to survey $\mathbf{P M}_{2.5}$ exposures in casinos on a statewide basis. Using a standardized protocol, we discreetly measured $\mathrm{PM}_{2.5}$ inside a selection of 36 casinos spread throughout California (including smoking areas, non-smoking areas, and restaurants), as well as outdoors. We also evaluated the effectiveness of different methods of separating the non-smoking from the smoking areas. Finally, as an initial exploration of whether the $\mathrm{PM}_{2.5}$ levels measured in California might also reflect casinos in other locations, we surveyed eight casinos in Reno, NV.

\section{Methods}

\section{Research Location and Sample Selection}

We surveyed 36 out of the 58 California Indian casinos (12 January to 25 December 2008), spanning locations across California (Figure 1). The locations, physical area, and the number of slot machines were tabulated for all 58 casinos from California Indian casino official websites. Each casino was classified based on the reported number of slot machines, as follows: small $(<500)$, medium (500-1400), or large ( $>1400$ slot machines). We sampled $10-15$ casinos in each size range during nine trips covering different parts of the state. On each trip, we visited as many casinos as possible over a 3-8-day period. In addition, we visited what is, to the best of our knowledge, the only smoke-free Indian casino in California. We also surveyed, for comparison, eight casinos in Reno, NV, using the same sampling protocol.

\section{Monitoring Protocol}

Most casinos were sampled on weekend or holiday evenings, when occupancy was high. On each casino visit, two or more investigators carried concealed real-time (i.e. continuous) aerosol monitors (AM510 SidePak laser photometer; TSI, Shoreview, MN, USA) with a short intake (Tygon tubing) protruding from a handbag or pocket, with data logged every $10 \mathrm{~s}$. The monitors were equipped with a $2.5-\mu \mathrm{m}$ sizeselective impactor.

The sampling locations at each casino included (1) outdoors (10-min periods before-and-after indoor sampling), (2) smoking slot machine areas (one 30-min period for small casinos, two 30-min periods for medium or large casinos), (3) non-smoking slot machine areas (30 min), and (4) restaurants $(\sim 1 \mathrm{~h})$. When sampling in smoking slot machine or nonsmoking slot machine locations, the investigators followed separate routes without returning to the same area. While outdoors or at restaurants, the investigators walked or sat side-by-side. The protocol included an additional collocation period $(\sim 10 \mathrm{~min})$ in a non-smoking slot machine area or restaurant in which two or more monitors were placed sideby-side to compare readings. A typical sampling event started at 1800-2000 hours and lasted for 1-4h, depending on the size and complexity of the casino.

\section{Quality Assurance of Aerosol Monitors}

The SidePak monitors determine the mass concentration from the intensity of scattered laser light. The monitor has a lower detection limit of $1 \mu \mathrm{g} / \mathrm{m}^{3}$ and an upper detection limit of $20,000 \mu \mathrm{g} / \mathrm{m}^{3}$ (TSI, 2008). The light scattering properties of particles vary with the size and composition of particles. Thus, it is essential to calibrate for the type of particles being sampled.

Before and after the field survey, we compared 12 SidePak monitors with gravimetric $\mathrm{PM}_{2.5}$ measurements. Fresh SHS was introduced into a $3 \mathrm{~m}^{3}$ chamber by a volunteer smoker, with four samples collected spanning a concentration range typical of indoor SHS levels $\left(40-400 \mu \mathrm{g} / \mathrm{m}^{3}\right)$. The relative humidity was $40 \%$ and $47 \%$, respectively, for the beforeand-after experiments.

For each SHS level, we collected pairs of gravimetric $\mathrm{PM}_{2.5}$ samples onto PTFE membrane filters $(47 \mathrm{~mm}$ diameter, 2- $\mu \mathrm{m}$ pore size, Pall Corp., Ann Arbor, MI, USA) downstream of a cyclone separator, using critical orifices to maintain a stable flow rate through each filter. Flow rates were measured before and after by a primary flow (bubble) calibrator (Gilian Instrument Corp., West Caldwell, NJ, USA).

Gravimetric filters were equilibrated for over $24 \mathrm{~h}$ at controlled relative humidity $(\sim 60 \%)$ and temperature $\left(70^{\circ} \mathrm{F}\right)$ and then weighed before-and-after sampling using a Mettler M3 Microbalance (Mettler-Toledo, Columbus, OH, USA).

The slope from a linear regression of the gravimetric $\mathrm{PM}_{2.5}$ versus each SidePak determined the multiplication factor (custom calibration factor) for rescaling the SidePak's data. For individual monitors, custom calibration factors ranged from 0.24 to 0.31 , with an average of 0.29 $(\mathrm{SD}=0.02)$ before and $0.28(\mathrm{SD}=0.02)$ after the field survey. $R^{2}$ values were all above 0.995 ; intercepts were close to zero. The average absolute deviation of calibration 


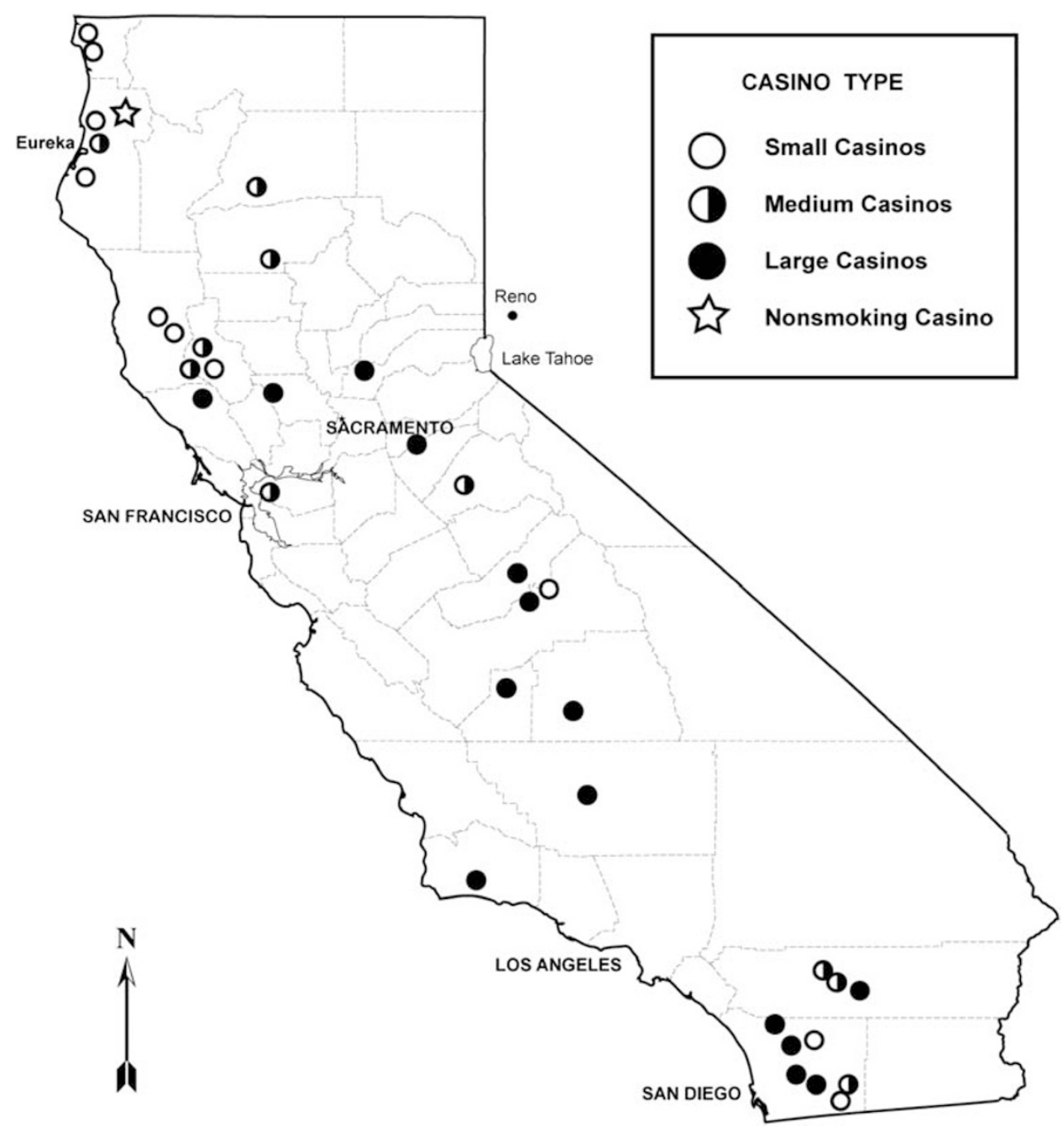

Figure 1. Map of California showing the locations and size categories of the 36 Indian casinos sampled.

factors between before-and-after experiments was $4 \%$ (range, $0-8 \% ; \mathrm{SD}=3 \%$ ). The average monitor precision was $3 \%$ (range, $1-12 \%$; $\mathrm{SD}=3 \%$ ). Our calibration factors, which were nearly identical to values found by Lee et al. (2008) for SHS with SidePak monitors, were applied to all casino measurements (relative humidity was always under $47 \%$ ). We scaled the measurements for each individual monitor by multiplying by the average of the before-and-after calibration factors.

\section{Counting Protocol and Casino Dimensions}

For each casino sampled, one investigator - the counter measured the casino dimensions, and counted slot machines, players, and active smokers, while one or more other investigators measured $\mathrm{PM}_{2.5}$ concentrations carrying concealed SidePak monitors. For smaller casinos, the counter counted every slot machine, player, and active smoker on the casino gaming floor by walking through smoking and non-smoking slot machine areas, for $30 \mathrm{~min}$ each. In casinos where counting the entire slot area was not feasible within $30 \mathrm{~min}$, the counter counted in randomly selected rows of slot machines throughout a large portion of the gaming area.

The occupancy (\%) of a casino gaming area was calculated as:

$$
\text { Occupancy }(\%)=\frac{\text { Total Number of Patrons }}{\text { Total Number of Slot Machines }} \times 100 \%
$$

The active smoking prevalence (\%) within the casino smoking area was defined as:

$$
\begin{aligned}
& \text { Active Smoking Prevalence }(\%) \\
& =\frac{\text { Total Number of Active Smokers }}{\text { Total Number of Patrons }} \times 100 \%
\end{aligned}
$$


We measured the horizontal dimensions of each casino by calibrated foot pacing. Each active smoker was counted only once. The area smoker density (active smokers/100 $\mathrm{m}^{2}$ ) was calculated as:

$$
\begin{aligned}
& \text { Area Smoker Density }\left(\text { active smokers } / 100 \mathrm{~m}^{2}\right) \\
& =\frac{100 \times \text { Total Number of Active Smokers }}{\text { Floor Area for Slot Machines }\left(\mathrm{m}^{2}\right)}
\end{aligned}
$$

\section{Data Analysis}

We applied descriptive statistics, linear regression analysis, analysis of variance (ANOVA), paired $t$-test, and the Shapiro-Wilks test for normality. SigmaPlot software, Version 11.0 (Systat Software, San Jose, CA, USA), and the $\mathrm{R}$ statistical package, Version 2.5.1 ( $\mathrm{R}$ Development Core Team, 2008) were used to perform the analyses.

\section{Results}

\section{California Casino Sample Characteristics}

The 58 casinos in California comprised 22 small, 15 medium, and 21 large ones. Our sample consisted of 11 small (including 1 smoke-free location), 10 medium, and 15 large casinos (Figure 1). The number of slot machines ranged from $\sim 200$ to over 3000 , and gaming floor areas ranged from $\sim 280 \mathrm{~m}^{2}$ to over $65,000 \mathrm{~m}^{2}$. All but four of the casinos had slot machines on a single floor. The temperature and relative humidity inside each casino, measured by a digital HygroThermometer (Sunleaves, Bloomington, IN, USA), was $70-80^{\circ} \mathrm{F}$ and $16-46 \%$, respectively.

Occupancy and active smoking prevalence were obtained for 35 casino visits, and area smoker density for 31 visits (Table 1). The occupancy on weekend and holiday evenings averaged $48 \%$ (range, 12-87\%); the active smoking prevalence averaged $11 \%$ (range, 5-25\%); and the area smoker density averaged 2.3 active smokers $/ 100 \mathrm{~m}^{2}$ (range, 0.5-5.3 active smokers $/ 100 \mathrm{~m}^{2}$ ). The mean occupancy in large casinos $(60 \%)$ was significantly higher (one-way ANOVA, $P<0.05)$ than in medium $(43 \%)$ and small casinos $(34 \%)$. However, the mean active smoking prevalence was significantly higher in small casinos $(16 \%$, versus $10 \%$ for large and medium casinos; $P<0.05)$. Differences in the mean area smoker density by casino size were not statistically significant.

\section{$\mathrm{PM}_{2.5}$ Concentrations in Smoking Areas}

Figure 2 shows an example of the $\mathrm{PM}_{2.5}$ concentrations as a function of time measured in a casino. As the two investigators moved independently through the smoking areas, momentary differences in concentrations were substantial; however, the average values for each location were quite similar.
The mean $\mathrm{PM}_{2.5}$ concentration over $0.5-1 \mathrm{~h}$ in the smoking sections ranged from 18 to $183 \mu \mathrm{g} / \mathrm{m}^{3}$ and averaged $63 \mu \mathrm{g} / \mathrm{m}^{3}$, with $50 \%$ of the visits exceeding $50 \mu \mathrm{g} / \mathrm{m}^{3} ; 20 \%$ exceeding $80 \mu \mathrm{g} / \mathrm{m}^{3}$; and $5 \%$ exceeding $100 \mu \mathrm{g} / \mathrm{m}^{3}$. The average $\mathrm{PM}_{2.5}$ concentrations in smoking areas among the three casino sizes were not significantly different.

Results from duplicate visits to four casinos (LE, LH, MB, and $\mathrm{MH}$, Table 1) showed variations in indoor $\mathrm{PM}_{2.5}$ concentrations between visits. These may be attributable, for example, to changes in smoking activity and/or occupancy immediately before the sampling events, which would change the initial background $\mathrm{PM}_{2.5}$ level. Three of the four first visits involved sampling and counting in just a portion of the casino; thus spatial heterogeneity could also be a factor.

Shorter-term exposures ranged much higher. For example, the maximum 1-min $\mathrm{PM}_{2.5}$ concentrations in casino smoking areas ranged from 44 to $291 \mu \mathrm{g} / \mathrm{m}^{3}$, with an average of the maxima of $116 \mu \mathrm{g} / \mathrm{m}^{3} \quad\left(\mathrm{SD}=55 \mu \mathrm{g} / \mathrm{m}^{3}\right)$. The maximum 1-min concentrations were $12-223 \mu \mathrm{g} / \mathrm{m}^{3}$ higher than the $0.5-1 \mathrm{~h}$ mean concentrations for the 39 visits in casino smoking areas (Supplementary Table S1).

The relationship between average incremental concentrations (concentration greater than the outdoors) in smoking areas and the area smoker densities is shown in Figure 3. Significant scatter in the data was expected due to differences in building characteristics that were not measured, such as the ventilation rate and ceiling heights. The linear regression results indicated area smoker density was positively associated with incremental smoking $\mathrm{PM}_{2.5}$ concentrations in California casinos with $r=0.52$. This result implied that $27 \%$ of the variation in the incremental $\mathrm{PM}_{2.5}$ concentrations could be explained by the area smoker density $\left(R^{2}=0.27\right.$; $n=31)$.

Figure 4 shows frequency distributions of the average $\mathrm{PM}_{2.5}$ measurements from the casinos at four locations: (1) smoking slot machine areas, (2) non-smoking slot machine areas, (3) outdoors, and (4) restaurants. The relative straightness of the frequency distributions in locations (1), (2), and (3) indicated a tendency toward a lognormal distribution. With the exception of one outlier, indoor smoking concentrations could be treated as normally distributed, but outdoor data did not fit a normal distribution (Shapiro-Wilks test; $P<0.001)$. The distribution of the relatively small sample of restaurant data $(n=20)$ appeared neither normal nor lognormal.

\section{Comparison of Smoking Versus Non-smoking Areas}

In 23 of the 35 smoking casinos, there were signs marking slot machine areas prohibiting smoking. The average $\mathrm{PM}_{2.5}$ concentration in the non-smoking areas was $22 \mu \mathrm{g} / \mathrm{m}^{3}$ (range, $1-81 \mu \mathrm{g} / \mathrm{m}^{3}$ ). We compared three methods of separation from the smoking areas: (1) no physical separation - the nonsmoking section was not in a separate room; (2) semiseparation - a separate non-smoking room but no closing 
Table 1. Summary statistics for the 36 California casinos in the statewide survey.

\begin{tabular}{|c|c|c|c|c|c|c|c|}
\hline \multirow[t]{2}{*}{ Casino ID $^{\mathrm{a}}$} & \multicolumn{4}{|c|}{ Average concentrations $\left(\mu \mathrm{g} / \mathrm{m}^{3}\right)$} & \multirow{2}{*}{$\begin{array}{l}\text { Occupancy } \\
(\%)\end{array}$} & \multirow{2}{*}{$\begin{array}{l}\text { Active smoking } \\
\text { prevalence }(\%)\end{array}$} & \multirow{2}{*}{$\begin{array}{c}\text { Area smoker density } \\
\text { (active smokers } / 100 \mathrm{~m}^{2} \text { ) }\end{array}$} \\
\hline & Smoking & Outdoor & Non-smoking & Restaurant & & & \\
\hline LA & 42.7 & 1.6 & 15.6 & 23.1 & 87.1 & 4.9 & 1.41 \\
\hline LB & 39.9 & 19.0 & 24.2 & 19.0 & 54.4 & 6.3 & 1.38 \\
\hline LC & 86.7 & 9.6 & 7.9 & 60.5 & 39.9 & 9.9 & 1.78 \\
\hline LD & 35.9 & 6.9 & 16.3 & 36.4 & 43.5 & 5.0 & 1.00 \\
\hline $\mathrm{LE}^{\mathrm{b}}$ & 40.8 & 9.5 & 25.5 & 18.8 & 52.8 & 7.5 & - \\
\hline $\mathrm{LE} 2^{\mathrm{c}}$ & 88.8 & 29.7 & 44.5 & 20.7 & 70.7 & 6.3 & 2.15 \\
\hline LF & 49.3 & 16.3 & 4.4 & 35.6 & 48.7 & 6.2 & 1.79 \\
\hline LG & 47.4 & 1.3 & - & 1.2 & 24.1 & 18.7 & 1.70 \\
\hline $\mathrm{LH}^{\mathrm{b}}$ & 42.0 & 8.5 & 3.9 & 34.4 & 47.1 & 8.9 & - \\
\hline $\mathrm{LH} 2^{\mathrm{c}}$ & 45.8 & 2.3 & 12.3 & 41.1 & 67.5 & 9.6 & 2.56 \\
\hline LI & 57.4 & 2.2 & 1.0 & 4.0 & 78.6 & 8.3 & 3.16 \\
\hline $\mathrm{LJ}$ & 74.0 & 4.2 & 9.8 & 5.1 & 69.0 & 14.1 & 4.54 \\
\hline LK & 109.6 & 5.3 & - & - & 63.5 & 14.1 & 4.18 \\
\hline LM & 72.1 & 4.4 & 6.5 & - & 62.5 & 17.5 & 5.09 \\
\hline $\mathrm{LN}$ & 62.4 & 1.3 & 57.2 & 34.6 & 87.2 & 7.7 & 3.15 \\
\hline LO & 77.0 & 7.4 & 75.6 & 56.9 & - & - & - \\
\hline LP & 75.8 & 1.3 & 24.6 & - & - & - & - \\
\hline MA & 73.4 & 3.3 & - & 64.1 & 37.0 & 18.9 & - \\
\hline $\mathrm{MB}^{\mathrm{b}}$ & 30.2 & 4.4 & 5.0 & 8.0 & 17.6 & 11.4 & - \\
\hline $\mathrm{MB} 2^{\mathrm{c}}$ & 21.2 & 3.4 & 6.6 & - & 24.1 & 10.3 & 0.98 \\
\hline $\mathrm{MC}$ & 45.7 & 12.2 & 16.5 & 19.4 & 39.6 & 9.1 & 1.39 \\
\hline MD & 60.5 & 2.9 & 32.6 & 43.7 & 19.6 & 10.8 & 1.27 \\
\hline ME & 66.0 & 4.5 & - & - & 29.1 & 5.0 & 0.48 \\
\hline MF & 68.2 & 7.9 & 81.2 & - & 73.0 & 10.0 & 1.84 \\
\hline MG & 94.1 & 2.4 & 32.1 & - & 77.8 & 8.6 & 3.16 \\
\hline MH & 83.8 & 5.4 & 8.4 & - & 52.8 & 8.8 & 1.51 \\
\hline $\mathrm{MH} 2^{\mathrm{c}}$ & 75.5 & 7.6 & 14.1 & - & 50.5 & 7.9 & 1.29 \\
\hline MI & 44.0 & 6.7 & 16.5 & - & - & - & - \\
\hline MJ & 52.7 & 6.7 & 11.2 & 22.5 & 51.8 & 7.4 & 1.07 \\
\hline SA & 48.2 & 5.8 & - & - & 5.7 & 10.0 & 0.46 \\
\hline SB & 29.2 & 5.1 & 23.1 & - & 23.7 & 25.4 & 3.96 \\
\hline $\mathrm{SC}$ & 76.6 & 13.6 & - & - & 41.8 & 14.4 & 3.82 \\
\hline SD & 63.7 & 3.5 & - & - & 62.2 & 15.7 & 5.25 \\
\hline SE & 70.8 & 7.4 & 25.2 & 20.4 & 33.1 & 19.8 & 2.91 \\
\hline $\mathrm{SF}$ & 64.5 & 3.2 & - & - & 43.5 & 9.9 & 1.68 \\
\hline SG & 42.1 & 7.3 & - & - & 20.1 & 21.4 & 1.83 \\
\hline $\mathrm{SH}$ & 105.0 & 4.4 & - & - & 61.0 & 13.1 & 4.86 \\
\hline SI & 18.5 & 0.8 & - & - & 16.9 & 10.2 & 0.93 \\
\hline SJ & 183.4 & 14.1 & - & - & - & - & - \\
\hline NS & - & 4.9 & 4.8 & - & 26.0 & - & - \\
\hline Mean $^{\text {d }}$ & 63.2 & 6.7 & 22.3 & 28.5 & 47.9 & 11.2 & 2.34 \\
\hline $\mathrm{SD}^{\mathrm{d}}$ & 29.4 & 5.7 & 20.7 & 18.4 & 21.5 & 5.1 & 1.41 \\
\hline
\end{tabular}

"IDs starting with "L", "M", and "S" indicate large, medium, and small casinos, respectively. "NS" is the only non-smoking casino.

${ }^{\mathrm{b}}$ Sampling and counting took place only in a portion of the casino, of an undetermined area.

${ }^{\mathrm{c}}$ Second visits for four casinos.

${ }^{\mathrm{d}}$ Calculated only for smoking casinos.

doors; and (3) complete physical separation — a separate room with closing doors. The average $\mathrm{PM}_{2.5}$ levels shown in Figure 5 for non-smoking areas with no separation (43 $\left.\mu \mathrm{g} / \mathrm{m}^{3}, n=8\right)$ and with semi-separation $\left(20 \mu \mathrm{g} / \mathrm{m}^{3}, n=9\right)$ were significantly higher than in areas with complete separation $\left(7.9 \mu \mathrm{g} / \mathrm{m}^{3}, n=10\right)$ (one-way ANOVA, $P<0.05$ ).
On average, the $\mathrm{PM}_{2.5}$ concentration in casino gaming areas with smokers was $36 \mu \mathrm{g} / \mathrm{m}^{3}$ higher than in nonsmoking gaming areas. In non-smoking areas with no separation, the average $\mathrm{PM}_{2.5}$ concentration was not significantly lower than the adjacent smoking areas. In contrast, $\mathrm{PM}_{2.5}$ concentrations in semi-separated or completely 


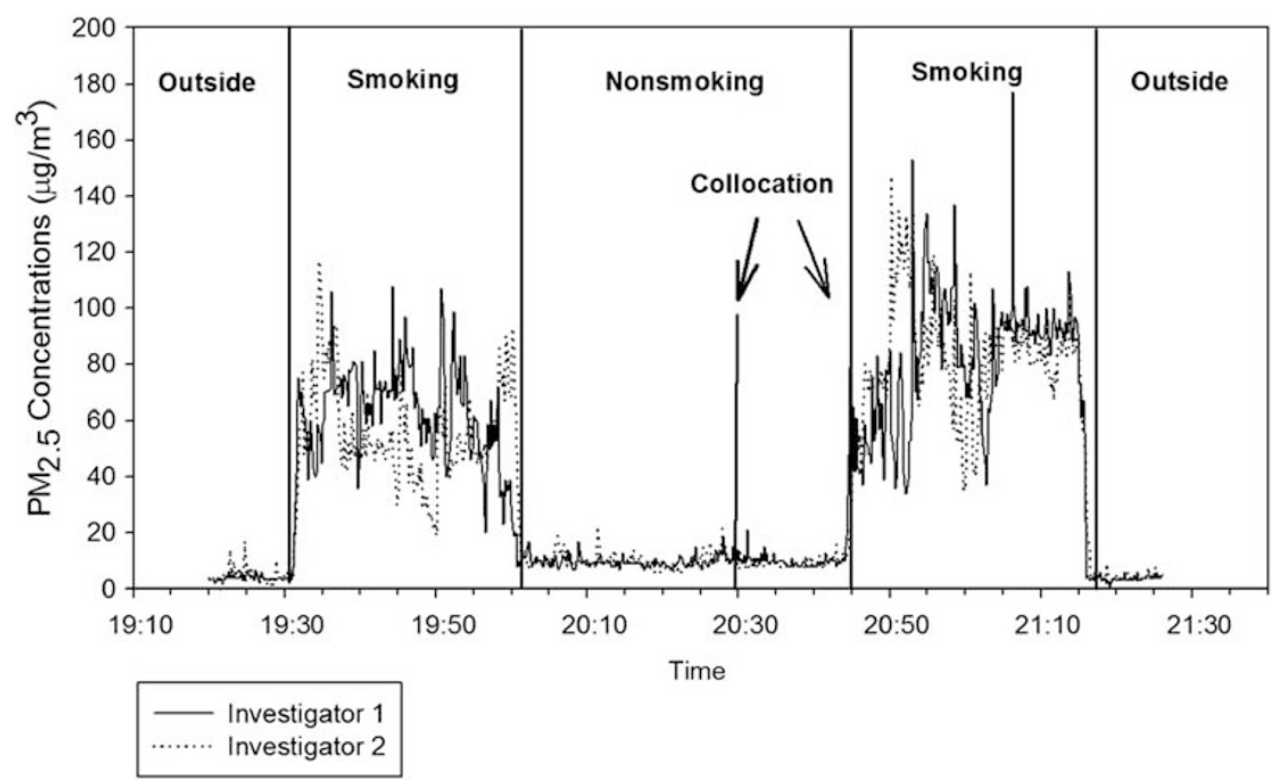

Figure 2. A time-series plot illustrating the sampling protocol performed by two investigators visiting three locations in a casino.

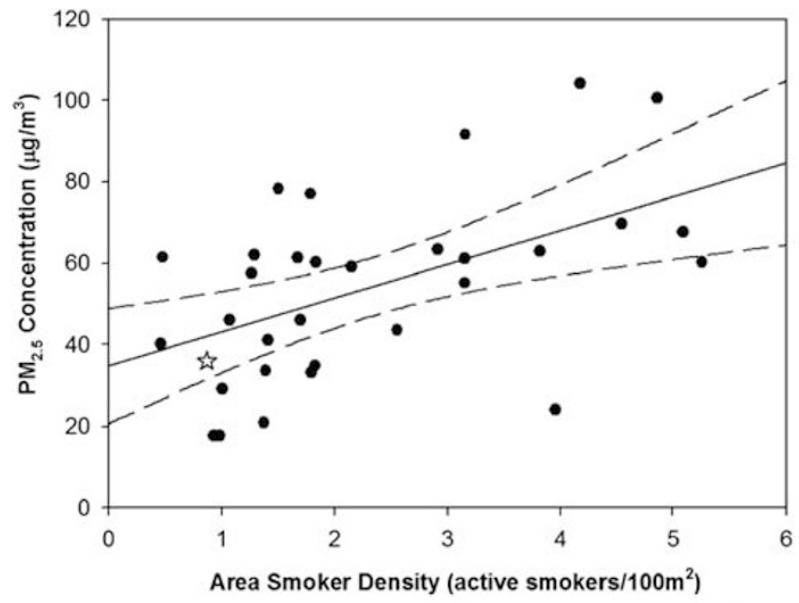

\begin{tabular}{|cl|}
\hline- & California measurements \\
- & Linear regression of California measurements \\
- & $95 \%$ Confidence Interval \\
it & The average of Reno measurements \\
\hline
\end{tabular}

Figure 3. Linear regression analysis of incremental $P M_{2.5}$ concentrations (concentrations above the outdoor levels) in the smoking areas of California casinos versus area smoking densities $(n=31)$. Regression equation: $P M_{2.5}$ concentration $=8.3 \times($ area smoker density $)+34.7$ $\left(R^{2}=0.27 ; \quad r=0.52\right)$. The star symbol represents the average incremental $\mathrm{PM}_{2.5}$ concentration for the average smoker density observed in seven Reno smoking casinos.

separated non-smoking areas were significantly lower than in the nearby smoking areas (paired $t$-test, $P<0.01$ ).

For those casinos that have both smoking and nonsmoking slot machine areas $(n=27)$, we examined how strongly the smoking areas affected the nearby non-smoking areas. We chose $60 \mu \mathrm{g} / \mathrm{m}^{3}$, a value close to the median $\left(57.4 \mu \mathrm{g} / \mathrm{m}^{3}\right)$ to subdivide these casinos into two groups of approximately equal size: the low concentration casinos $(n=14)$ had average $\mathrm{PM}_{2.5}$ levels below $60 \mu \mathrm{g} / \mathrm{m}^{3}$ in the smoking areas, and the high concentration casinos $(n=13)$ were above $60 \mu \mathrm{g} / \mathrm{m}^{3}$ in the smoking areas (Figure 6). For all three non-smoking separation types, low concentration casinos had the lower average $\mathrm{PM}_{2.5}$ levels. The difference in the average non-smoking $\mathrm{PM}_{2.5}$ level between low concentration casinos and high concentration casinos was greatest for areas with no separation, and smallest for areas with complete physical separation. Thus, $\mathrm{PM}_{2.5}$ levels in smoking areas had a greater impact on adjacent nonsmoking areas if no physical barriers existed between the two sections.

\section{$P M_{2.5}$ Concentrations for Outdoors, Restaurants, Other \\ Locations}

The $\mathrm{PM}_{2.5}$ concentrations measured outdoors averaged $7 \mu \mathrm{g} / \mathrm{m}^{3}$; with one exception (during a nearby forest fire), all outdoor locations were below $19 \mu \mathrm{g} / \mathrm{m}^{3}$ (Table 1). On average, the $\mathrm{PM}_{2.5}$ concentration in indoor smoking areas was $56 \mu \mathrm{g} / \mathrm{m}^{3}$ higher than outdoors. Compared with outdoor measurements, the average $\mathrm{PM}_{2.5}$ concentration in nonsmoking areas was $36 \mu \mathrm{g} / \mathrm{m}^{3}$ higher for no separation, $12 \mu \mathrm{g} / \mathrm{m}^{3}$ higher for semi-separation (both statistically significant, $P<0.01$ ), and $1 \mu \mathrm{g} / \mathrm{m}^{3}$ higher for complete separation (not statistically significant).

The mean $\mathrm{PM}_{2.5}$ level of $29 \mu \mathrm{g} / \mathrm{m}^{3}$ in the non-smoking restaurants $(n=20)$, where children were often present, was $22 \mu \mathrm{g} / \mathrm{m}^{3}$ above the average outdoor concentration, and $7 \mu \mathrm{g} / \mathrm{m}^{3}$ higher than the non-smoking gaming areas.

In three of the smoking casinos, the mean $\mathrm{PM}_{2.5}$ concentrations in non-smoking poker rooms were 64, 22, 

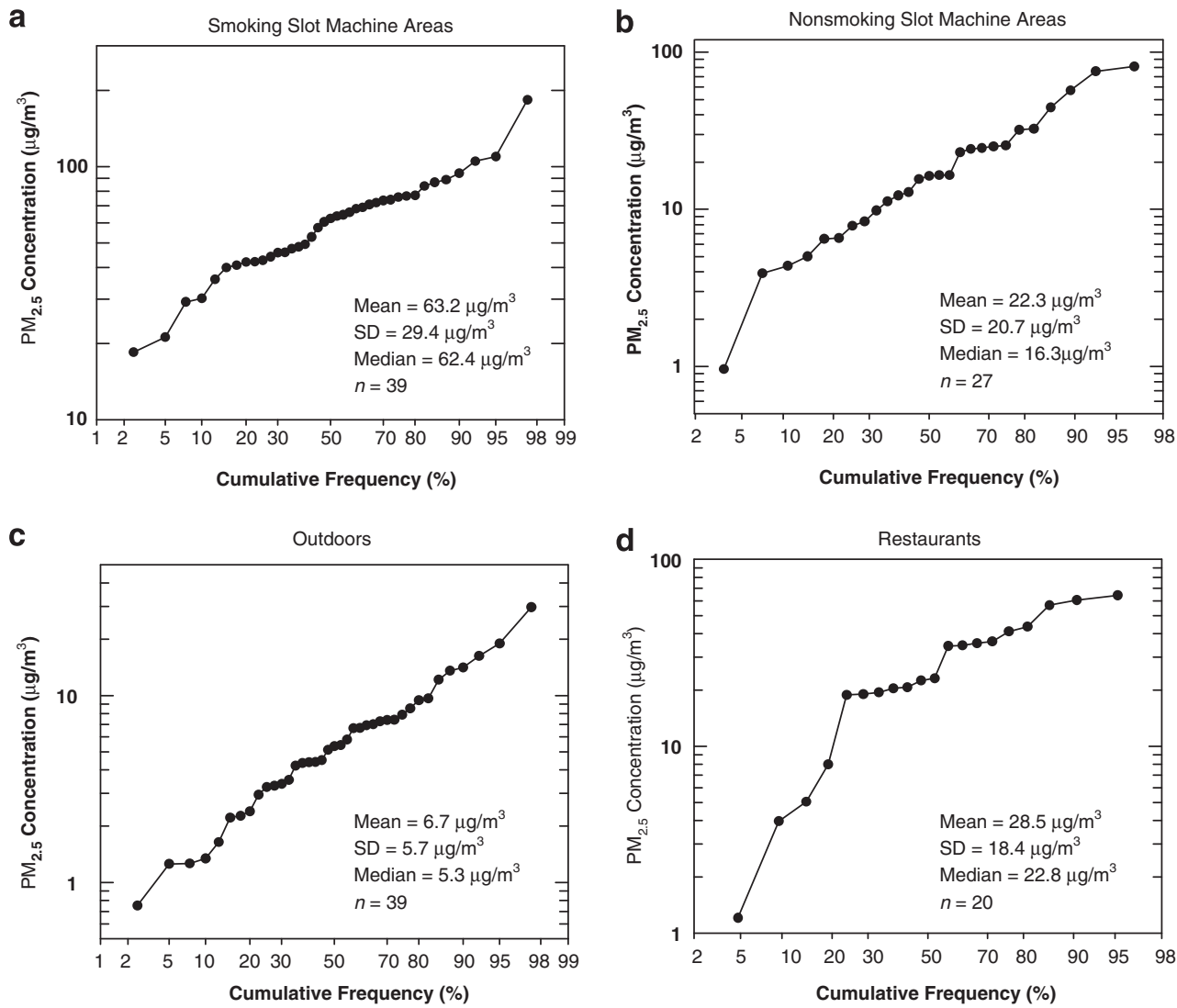

Figure 4. Frequency distribution plots for $\mathrm{PM}_{2.5}$ concentrations in the (a) smoking areas, (b) non-smoking areas, (c) outdoors, and (d) restaurants of the 39 visits to 35 smoking Indian casinos in California.

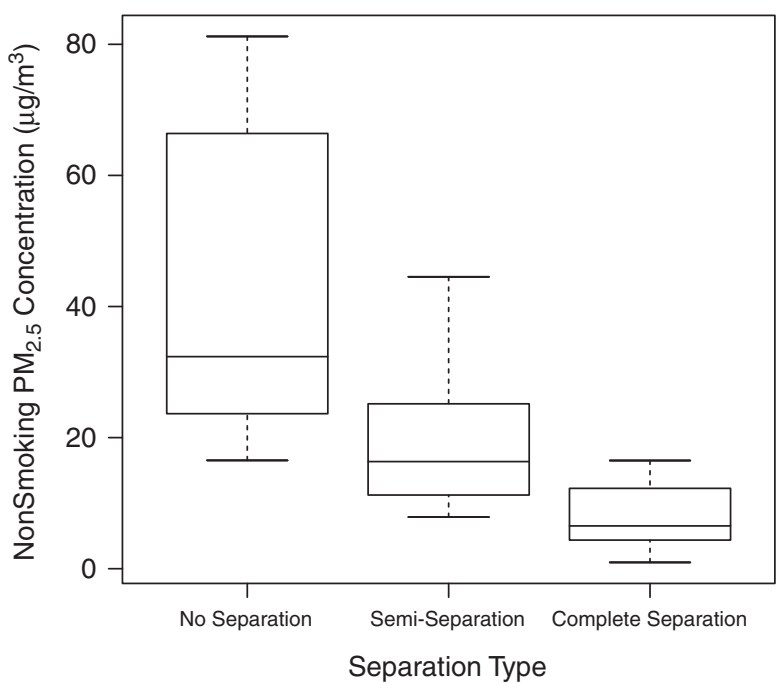

Figure 5. Box plots comparing average $\mathrm{PM}_{2.5}$ levels in casino nonsmoking gaming areas stratified by three separation methods. Boxes represent the interquartile range (25th-75th percentiles, median indicated by horizontal line), and whiskers extend to the 5th and 95th percentiles.

and $14 \mu \mathrm{g} / \mathrm{m}^{3}$. Other non-smoking locations measured included a casino delicatessen $\left(11 \mu \mathrm{g} / \mathrm{m}^{3}\right)$, bowling alley $\left(31 \mu \mathrm{g} / \mathrm{m}^{3}\right)$, and bingo room $\left(10 \mu \mathrm{g} / \mathrm{m}^{3}\right)$.

\section{A Smoke-Free Casino}

There was one small casino in California that banned smoking indoors (see star symbol on map in Figure 1). The average $\mathrm{PM}_{2.5}$ level inside this casino was $5.4 \mu \mathrm{g} / \mathrm{m}^{3}$, comparable to the mean outdoor concentration $\left(5.5 \mu \mathrm{g} / \mathrm{m}^{3}\right)$. The indoor $\mathrm{PM}_{2.5}$ level in this smoke-free casino was less than $1 / 10$ th the average in the smoking areas of the 35 other casinos, and 1/4th the average in the non-smoking areas of the casinos that allowed smoking.

\section{$\mathrm{PM}_{2.5}$ Concentrations in Reno Casinos}

To initially explore, using the same sampling and monitoring protocol, whether the relationship seen in the California casinos between incremental $\mathrm{PM}_{2.5}$ concentrations and area smoker density might hold for other locations, we also measured eight non-Indian casinos in Reno, including one smoke-free casino (Supplementary Tables S2 and S3).

For the seven Reno smoking casinos, the average $\mathrm{PM}_{2.5}$ level in the smoking areas during weekend evenings was $37 \mu \mathrm{g} / \mathrm{m}^{3}$, 30 times as high as outdoors $\left(1.2 \mu \mathrm{g} / \mathrm{m}^{3}\right)$. The restaurants averaged $17 \mu \mathrm{g} / \mathrm{m}^{3} \quad(n=5)$. The mean $\mathrm{PM}_{2.5}$ levels for designated non-smoking areas were 10 and $7 \mu \mathrm{g} / \mathrm{m}^{3}$ for two areas with semi-separation, lower than in one other area with no physical separation $\left(22 \mu \mathrm{g} / \mathrm{m}^{3}\right)$. Casino occupancy averaged $38 \%$ (range, $31-49 \%$ ), active smoking 

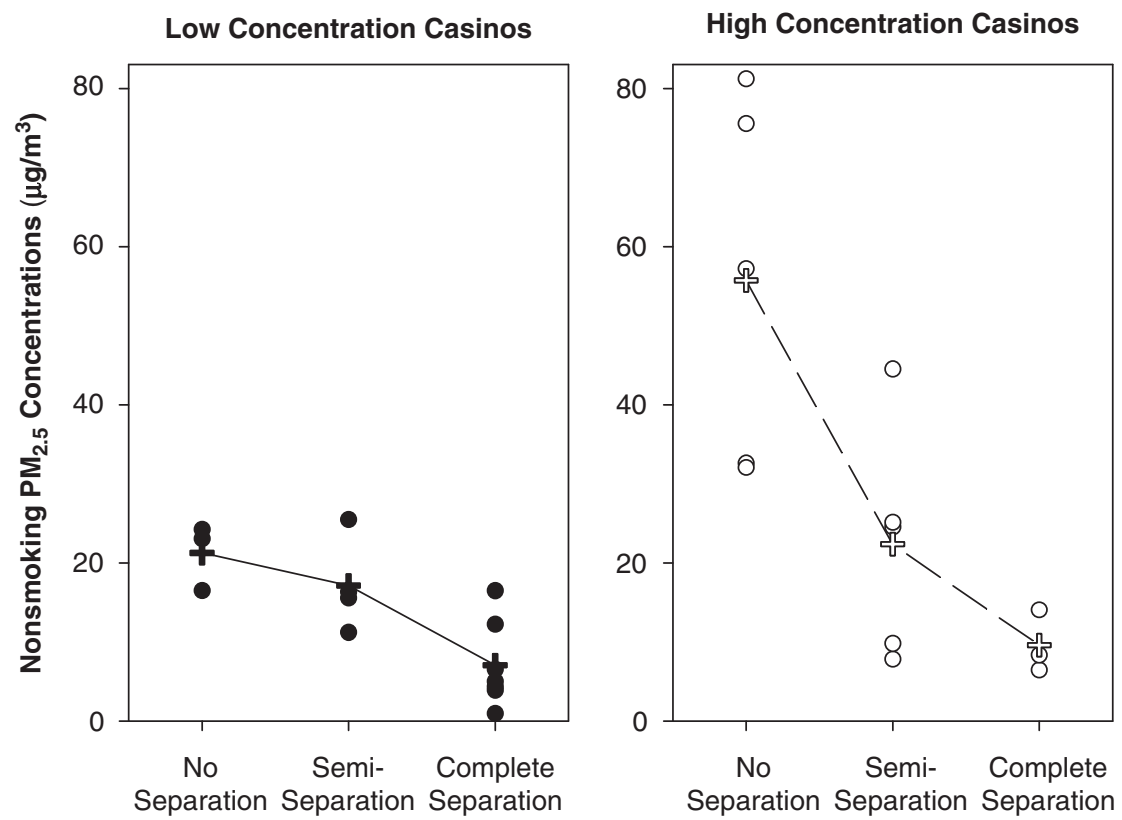

Separation Type

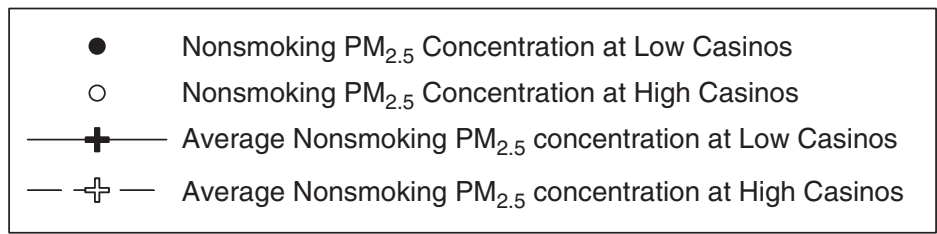

Figure 6. Interaction effects of $\mathrm{PM}_{2.5}$ levels in casino smoking areas and three methods of separating the non-smoking areas on $\mathrm{PM}_{2.5}$ levels in casino non-smoking gaming areas. Average $\mathrm{PM}_{2.5}$ concentrations in smoking slot machine areas for low concentration casinos were below $60 \mu \mathrm{g} / \mathrm{m}^{3}$ and for high concentration casinos were above $60 \mu \mathrm{g} / \mathrm{m}^{3}$.

prevalence averaged $10 \%$ (range, $7-12 \%$ ), and area smoker density averaged 0.9 active smokers $/ 100 \mathrm{~m}^{2}$ (range, $0.4-1.3$ active smokers $/ 100 \mathrm{~m}^{2}$ ). Temperature and relative humidity inside these casinos were $70-75^{\circ} \mathrm{F}$ and $20-30 \%$, respectively.

The average $\mathrm{PM}_{2.5}$ concentration inside the one non-smoking Reno casino was $0.6 \mu \mathrm{g} / \mathrm{m}^{3}$, compared with an average outdoor concentration of $1.2 \mu \mathrm{g} / \mathrm{m}^{3}$; the occupancy was $20 \%$.

We compared the $\mathrm{PM}_{2.5}$ concentrations in the smoking areas of Reno casinos to California casinos, accounting for smoker density (Figure 3). The average incremental smoking concentration of Reno casinos (shown as a star) falls within the $95 \%$ confidence interval about the mean for the California casinos. Thus, when the effects of outdoor concentrations and smoker density are included, the average $\mathbf{P M}_{2.5}$ concentration measured in smoking areas of these Reno casinos is consistent with the relationship for the means of California casinos.

\section{Discussion}

The active smoking prevalence averaged $11 \%$ for California casinos and $10 \%$ for Reno casinos, higher than the average of $8.5 \%$ in a Delaware casino (Repace, 2004), and 7\% at casinos in Las Vegas, Reno, and Lake Tahoe (Pritsos et al., 2008) and in Pennsylvania (Repace, 2009). Repace (2009) estimates the "adult smoking prevalence" as three times the active smoking prevalence, making the adult smoking prevalence in California smoking casinos much higher than the state's adult smoking prevalence of 13\% (CDPH, 2008).

We found a positive correlation between area smoker density and incremental $\mathrm{PM}_{2.5}$ concentration. However, the area smoker density alone is not sufficient to predict incremental $\mathrm{PM}_{2.5}$ concentrations. Measurements of other building characteristics, such as the ventilation rates and ceiling heights, are necessary to better interpret indoor $\mathrm{PM}_{2.5}$ levels. For example, Repace (2009) has used the indoor and outdoor $\mathrm{CO}_{2}$ difference, along with occupancy counts, to assess ventilation rates in casinos, and the results suggest that the $\mathrm{PM}_{2.5}$ concentration is inversely proportional to the ventilation rate per occupant. In an unpublished analysis, Repace and coworkers found that the $R^{2}$ value of the regression between incremental $\mathrm{PM}_{2.5}$ concentrations and the ratio of smoker density to ventilation rate per occupant was close to $0.8(n=7)$. Measuring $\mathrm{CO}_{2}$ concentrations and 
including ventilation estimates in regression analysis is expected to improve our ability to explain variation in $\mathrm{PM}_{2.5}$ levels.

The only short-term U.S. EPA National Air Quality Standard for $\mathrm{PM}_{2.5}$ is a 24-h standard for ambient (outdoor) levels, set at $35 \mu \mathrm{g} / \mathrm{m}^{3}$. We found that $90 \%$ of the average 0.5-1 h $\mathrm{PM}_{2.5}$ concentrations measured on weekend and holiday evenings in the smoking areas of California casinos exceeded $35 \mu \mathrm{g} / \mathrm{m}^{3}$. If we consider the highest $1 \mathrm{~h}$ average $\mathrm{PM}_{2.5}$ concentration of $183 \mu \mathrm{g} / \mathrm{m}^{3}$ measured in a casino smoking area, a person (such as an employee) spending $8 \mathrm{~h}$ in the casino with zero exposure for the remaining $16 \mathrm{~h}$ would experience a 24-h exposure of $61 \mu \mathrm{g} / \mathrm{m}^{3}$, well above the U.S. EPA standard.

The range of mean $\mathrm{PM}_{2.5}$ concentrations for the California casino smoking areas was similar to the range for three Las Vegas (CDC, 2009), one Delaware (Repace, 2004), and three Pennsylvania casinos (Repace, 2009). Variations among study sites were expected due to differences in smoker densities, ventilation, and building characteristics. Variations in $\mathrm{PM}_{2.5}$ for duplicate visits to a given study site also were expected, and were observed for four casinos. In addition to variables such as smoker activity, occupancy, and spatial heterogeneity, differences in the initial indoor concentrations (e.g. due to higher or lower smoking activity before the start of sampling) could also contribute. Ott et al. (1996) also found substantial variability in respirable particle concentrations for 26 visits to a sports tavern that allowed smoking.

The fine particle levels we observed in casino smoking areas were also comparable to levels previously observed in other public places. For example, the study measuring $\mathrm{PM}_{3.5}$ on 26 visits to a sports tavern before the California smoking ban yielded concentrations of $25-180 \mu \mathrm{g} / \mathrm{m}^{3}$ with an incremental mean concentration of $57 \mu \mathrm{g} / \mathrm{m}^{3}$ (Ott et al., 1996), almost identical to the incremental mean concentration of $56 \mu \mathrm{g} / \mathrm{m}^{3}$ for our Indian casinos. In Italy, before a smoking ban, average $\mathrm{PM}_{2.5}$ concentrations included $47 \mu \mathrm{g} / \mathrm{m}^{3}$ in 14 bars, $111 \mu \mathrm{g} / \mathrm{m}^{3}$ in 12 restaurants, and $150 \mu \mathrm{g} / \mathrm{m}^{3}$ in 8 video game parlors (Valente et al., 2007). A German study reported median $\mathrm{PM}_{2.5}$ levels of $178 \mu \mathrm{g} / \mathrm{m}^{3}$ for 11 restaurants, and $192 \mu \mathrm{g} / \mathrm{m}^{3}$ for 7 pubs (Bolte et al., 2008). In smoking areas of two coffee shops in Taiwan, median $\mathrm{PM}_{2.5}$ concentrations were 106 and $80 \mu \mathrm{g} / \mathrm{m}^{3}$ (Lung et al., 2004). In UK bars and pubs with mechanical ventilation, the median $\mathrm{PM}_{2.5}$ concentration was $57 \mu \mathrm{g} / \mathrm{m}^{3}$ when smoking was allowed (Carrington et al., 2003). In Texas, before a smoking ban, the average $\mathrm{PM}_{2.5}$ level was $151 \mu \mathrm{g} / \mathrm{m}^{3}$ in 17 bars (Waring and Siegel, 2007).

Our findings indicate that non-smoking areas with no physical barriers provided little protection from exposures to SHS; this has also been reported for other public locations (Cains et al., 2004; Lung et al., 2004). Designating separate rooms as non-smoking areas, especially with closed doors, was somewhat effective in reducing $\mathrm{PM}_{2.5}$ levels. However, for 23 of 27 visits, the mean $\mathrm{PM}_{2.5}$ levels in indoor non-smoking areas were higher than outdoors. Similarly, Cains et al. (2004) reported that separated non-smoking rooms in Australian social and gaming clubs reduced $\mathrm{PM}_{10}$ concentrations more than nonsmoking areas contiguous with the smoking areas. Other previous studies (Carrington et al., 2003; Cenko et al., 2004) have concluded that a separated ventilation system was not effective, and that exposure to SHS in non-smoking areas may still represent an appreciable health risk.

Determining exposure is essential for assessing health effects. There has been increasing interest in health effects associated with very short-term (i.e. a few minutes) exposure to SHS (Barnoya and Glantz, 2005). In 2001, Pope et al. found that a 2-h exposure to SHS with an average $\mathrm{PM}_{3}$ level of $78 \mu \mathrm{g} / \mathrm{m}^{3}$ was associated with decrements in heart rate variability and increased cardiac vulnerability. In our study, 7 out of 39 casino visits of $0.5-1 \mathrm{~h}$ had mean $\mathrm{PM}_{2.5}$ concentrations higher than $78 \mu \mathrm{g} / \mathrm{m}^{3}$. A comprehensive review (Pope and Dockery, 2006) found evidence that a $20 \mu \mathrm{g} / \mathrm{m}^{3}$ increase in long-term average outdoor $\mathrm{PM}_{2.5}$ concentration is associated with a $20 \%$ increase in cardiopulmonary mortality. If the toxicity of $\mathrm{PM}_{2.5}$ from SHS is similar to outdoor $\mathrm{PM}_{2.5}$, then frequent exposure to the average elevation of $56 \mu \mathrm{g} / \mathrm{m}^{3}$ observed in smoking areas of California casinos is likely to be associated with significant increases in adverse health effects.

\section{Conclusions}

$\mathrm{PM}_{2.5}$ concentrations in the smoking areas of 35 smoking Indian casinos in California averaged $63 \mu \mathrm{g} / \mathrm{m}^{3}, 3$ times as high as in the non-smoking areas $\left(22 \mu \mathrm{g} / \mathrm{m}^{3}\right), 2$ times as high as in casino restaurants $\left(29 \mu \mathrm{g} / \mathrm{m}^{3}\right)$, and $>10$ times as high as in the smokefree casino $\left(5.4 \mu \mathrm{g} / \mathrm{m}^{3}\right)$. These results, taken together, strongly indicate that SHS is the predominant cause of elevated $\mathrm{PM}_{2.5}$ concentrations in the casinos sampled. In addition, we found:

- Average concentrations in indoor smoking areas, nonsmoking areas, and restaurants were, respectively, 56, 15 and $22 \mu \mathrm{g} / \mathrm{m}^{3}$ above outdoor levels.

- In contrast, the two non-smoking casinos measured (one in Reno and one in California) had indoor concentrations that were as low as outdoors.

- For $90 \%$ of the casino visits, mean concentrations in smoking areas averaged over $0.5-1 \mathrm{~h}$ exceeded $35 \mu \mathrm{g} / \mathrm{m}^{3}$.

- Separated non-smoking rooms with closing doors had lower $\mathrm{PM}_{2.5}$ concentrations than rooms with open doors or non-smoking areas with no physical separation.

- The indoor $\mathrm{PM}_{2.5}$ mean concentration of 7 Reno nonIndian casinos was consistent with mean concentrations in the smoking areas of 35 California Indian casinos when adjusted for outdoor levels and area smoker density. 
The results of this study represent $\mathrm{PM}_{2.5}$ concentrations measured in single visits on weekend and holiday evenings in slot machine areas and restaurants of California Indian casinos. As our results illuminate the potential health risks for people spending time inside smoking casinos, they are valuable to casino workers, unions, owners, the general public, and government agencies, who make decisions on smoking bans. Exposure to the average elevation of $56 \mu \mathrm{g} / \mathrm{m}^{3}$ observed in smoking areas of California casinos is likely to be associated with significant increases in adverse health effects. In addition to characterizing $\mathrm{PM}_{2.5}$ concentrations at other times and locations, future studies should more intensively examine casino worker exposures, the impact of building characteristics, and particle levels before-and-after smoking bans.

\section{Conflict of interest}

Mr. Repace is an international secondhand smoke consultant to governmental and private entities, and has served as an expert witness in litigation between workers injured by secondhand smoke and casinos, as well as the tobacco industry. The other authors declare no conflict of interest.

\section{Acknowledgements}

We acknowledge the Flight Attendant Medical Research Institute for supporting this research, and Le verne McClure, John Moye and Thivanka Muthumalage for sampling some casinos. This paper represents the views of the authors and not necessarily those of the sponsor. Mention of commercial products does not constitute endorsement or recommendation.

\section{References}

Abrams S., Mahoney M., Hyland A., Cummings M., Davis W., and Song L. Early evidence on the effectiveness of clean indoor air legislation in New York State. Am J Public Health 2006: 96: 296-298.

Anderson K., Kliris J., Murphy L., Carmella S., Han S., and Link C., et al. Metabolites of a tobacco-specific lung carcinogen in nonsmoking casino patrons. Cancer Epidem Biomar 2003: 12: 1544-1546.

ANRF (American Nonsmokers' Rights Foundation). Smoke-free lists, maps and data. Available at http://www.no-smoke.org accessed 11 May 2009, 2009.

Barnoya J., and Glantz S. Cardiovascular effects of secondhand smoke nearly as large as smoking. Circulation 2005: 111: 2684-2698.

Bolte G., Heitmann D., Kiranoglu M., Schierl R., Diemer J., Koerner W., and Fromme H. Exposure to environmental tobacco smoke in German restaurants, pubs, and discotheques. $J$ Expo Sci Environ Epidemiol 2008: 18: 262-271.

Brennan P., Buffler P.A., Reynolds P., Wu A.H., Wichmann H.E., and Agudo A., et al. Secondhand smoke exposure in adulthood and risk of lung cancer among never smokers: a pooled analysis of two large studies. Int $J$ Cancer 2004: 109: 125-131.

Cains T., Cannata S., Poulos R., Ferson M.J., and Stewart B.W. Designated "no smoking" areas provide from partial to no protection from environmental tobacco smoke. Tob Control 2004: 13: 17-22.

California EPA (Environmental Protection Agency). Proposed identification of environmental tobacco smoke as a toxic air contaminant. Available at http://www.arb.ca.gov/regact/ets2006/ets2006.htm accessed 8 December 2008, 2006

Carrington J., Watson A., and Gee I. The effects of smoking status and ventilation on environmental tobacco smoke concentrations in public areas of UK pubs and bars. Atmos Environ 2003: 37: 3255-3266.

CDC. Environmental and biological assessment of environmental tobacco smoke exposure among casino dealers. Health Hazard Evaluation Report. Available at http://www.cdc.gov/niosh/hhe/ accessed 9 June 2009, 2009.

CDC (Center for Disease Control and Prevention). Annual smoking-attributable mortality, years of potential life lost, and productivity losses-U.S., 1997-2001. MMWR 2005: 54: 625-628.

CDPH (California Department of Public Health Services). California adult smoking prevalence. Available at http://www.cdph.ca.gov accessed 28 May 2009, 2008

Cenko C., Pisaniello D., and Esterman A. A study of environmental tobacco smoke in south Australian pubs, clubs and cafes. Int J Environ Heal R 2004: 14: 3-11.

Dunstan R. Indian casinos in California. California State Library. Available at http://www.library.ca.gov/crb/98/15/98015.pdf accessed 25 August 2009, 1998.

Hammond S.K. Exposure of U.S. workers to environmental tobacco smoke. Environ Health Perspect 1999: 107(Suppl 2): 329-340.

Hyland A., Travers M.J., Dresler C., Higbee C., and Cummings K.M. A 32-country comparison of tobacco smoke derived particle levels in indoor public places. Tob Control 2008: 17: 159-165.

Kado N.Y., Mccurdy S.A., Tesluk S.J., Hammond S.K., Hsieh D., and Jones J., et al. Measuring personal exposure to airborne mutagens and nicotine in environmental tobacco smoke. Mutat Res 1991: 261: 75-82.

Koh H., Joossen L., and Connolly G. Making smoking history worldwide. $N$ Engl J Med 2007: 365: 1496-1498.

Larsson M., Boëthius G., Axelsson S., and Montgomery S. Exposure to environmental tobacco smoke and health effects among hospitality workers in Sweden - before and after the implementation of a smoke-free law. Scand $J$ Work Environ Health 2008: 34: 267-277.

Lee K., Hahn E., Okoli C., Repace J., and Troutman A. Differential impacts of smoke-free laws on indoor air quality. $J$ Environ Health 2008: 40: 24-30.

López M.J., Nebot M., Albertini M., Birkui P., Centrich F., and Chudzikova M., et al. Secondhand smoke exposure in hospitality venues in Europe. Environ Health Perspect 2008: 116: 1469-1472.

Lung S.C.C., Wu M.J., and Lin C.C. Customers' exposure to $\mathrm{PM}_{25}$ and polycyclic aromatic hydrocarbons in smoking/nonsmoking sections of 24-h coffee shops in Taiwan. J Expo Anal Environ Epidemiol 2004: 14: $529-535$.

Nazaroff W.W., and Singer B.C. Inhalation of hazardous air pollutants from environmental tobacco smoke in US residences. $J$ Expo Anal Environ Epidemiol 2004: 14: S71-S77.

Ott W., Switzer P., and Robinson J. Particle concentrations inside a tavern before and after prohibition of smoking: evaluating the performance of an indoor air quality model. J Air Waste Manage Assoc 1996: 46: 1120-1134.

Pilkington P., Gray S., and Gilmore A. Health impacts of exposure to second hand smoke (SHS) amongst a highly exposed workforce: survey of London casino workers. BMC Public Health 2007: 7: 257-264.

Pope C.A., and Dockery D.W. Health effects of fine particulate air pollution: lines that connect. J Air Waste Manage Assoc 2006: 56: 709-742.

Pope C.A., Eatough D.J., Gold D.R., Pang Y., Nielsen K.R., and Nath P., et al Acute exposure to environmental tobacco smoke and heart rate variability. Environ Health Perspect 2001: 109: 711-716.

Pope C.A., Ezzati M., and Dockery D. Fine-particulate air pollution and life expectancy in the United States. N Engl J Med 2009: 360: 376-386.

Pritsos C.A., Pritsos K.L., and Spears K.E. Smoking rates among gamblers at Nevada casinos mirror US smoking rate. Tob Control 2008: 17: 82-85.

R Development Core Team. $R$ : A Language and Environment for Statistical Computing. Version 2.5.1. Vienna, Austria, 2008.

Repace J. Respirable particles and carcinogens in the air of Delaware hospitality venues before and after a smoking ban. J Occup Environ Med 2004: 46: 887-905.

Repace J. Secondhand smoke in Pennsylvania casinos: a study of nonsmokers' exposure, dose, and risk. Am J Public Health 2009: 99: 1478-1485.

Siegel M., and Skeer M. Exposure to secondhand smoke and excess lung cancer mortality risk among workers in the "5 B's": bars, bowling alleys, billiard halls, betting establishments and bingo parlours. Tob Control 2003: 12: 333-338. 
Surgeon General. U.S. Department of Health and Human Services. The health consequences of involuntary exposure to tobacco smoke: a report of the Surgeon General. Available at http://www.surgeongeneral.gov/library accessed 9 May 2009, 2006

Trout D., Decker J., Mueller C., Bernett J., and Pirkle J. Exposure of casino employees to environmental tobacco smoke. J Occup Environ Med 1998: 40: 270-276.

TSI. Model AM510 SidePak ${ }^{\mathrm{TM}}$ Personal Aerosol Monitor User Guide, 1980456, Revision F. Shoreview, MN: TSI Incorporated. Available at http:// www.tsi.com/uploadedFiles/Product_Information/Literature/Manuals/ SidePak_AIM510-1980456f.pdf accessed 24 November 2009, 2008.

U.S. EPA. Particulate matter standards. Available at http://www.epa.gov accessed 9 May 2009, 2006.

Valente P., Forastiere F., Bacosi A., Cattani G., Di Carlo S., and Ferri M., et al. Exposure to fine and ultrafine particles from secondhand smoke in public places before and after the smoking ban, Italy 2005. Tob Control 2007: 16: 312-317.
Wakefield M., Cameron M., Inglis G., Lecher T., and Durkin S. Secondhand smoke exposure and respiratory symptoms among casinos, club and office workers in Victoria, Australia. J Occup Environ Med 2005: 47: 698-703.

Waring M.S., and Siegel J.A. An evaluation of the indoor air quality in bars before and after a smoking ban in Austin, Texas. J Expo Anal Environ Epidemiol 2007: 17: 260-268.

WHO (World Health Organization). Framework convention on tobacco control Available at http://www.who.int/fctc/en/ accessed 27 May 2009, 2009.

This work is licensed under the Creative Commons Attribution-NonCommercial-No Derivative Works SOMERTGHISRESE 3.0 Unported License. To view a copy of this license, visit http:// creativecommons.org/licenses/by-nc-nd/3.0/ 